\title{
A FORMAÇÃO CONTÍNUA DE PROFESSORES DE LÍNGUA PORTUGUESA EM CONTEXTO DE MATO GROSSO/MT
}

\author{
Helenice Joviano Roque Faria ${ }^{1}$ \\ https://orcid.org/0000-0003-4209-516X
}

Resumo: $\mathrm{O}$ artigo propõe discutir a política formativa de professores no contexto do Estado de Mato Grosso (MT). Para tal, observo os documentos orientadores e ouço 02 professoras, egressas do ProfLetras, efetivas da Rede de Educação Básica. Pelas análises indico potencializar o diálogo e eleger formas que fortaleçam os conhecimentos dos profissionais docentes no sentido de contribuir nas/para as práticas diárias de linguagem. Assim, refletir sobre os desafios e as contribuições impostas pelas esferas governamentais, interpretar a formulação, a organização da agenda formativa e verificar os resultados dessas ações podem contribuir para mudanças que corroboram para o (re)posicionamento das práticas situadas de ensino da Língua Portuguesa.

Palavras-chave: política formativa; portuguesa; mato grosso.

${ }^{1}$ Doutora em Linguística pela Universidade de Brasília - UnB. Membro do Grupo de Estudos Críticos e Avançados em Linguagem - GECAL CNPq/UnB e GEPLIAS - UNEMAT-Sinop/MT. E-mail: helenicefariaj@gmail.com. 


\section{THE CONTINUING EDUCATION OF PORTUGUESE LANGUAGE TEACHERS IN THE CONTEXT OF MATO GROSSO/MT}

Abstract: The article proposes to discuss the teacher education policy in the context of the State of Mato Grosso (MT). To do so, I observe the guiding documents and listen to two teachers, graduates of ProfLetras, effective in the Basic Education Network. Through the analyses I indicate that we should strengthen the dialogue and choose ways to strengthen the knowledge of the teaching professionals in order to contribute to the daily language practices. Thus, reflecting on the challenges and contributions imposed by governmental spheres, interpreting the formulation, the organization of the formative agenda and verifying the results of these actions can contribute to changes that corroborate for the (re)positioning of the situated practices of Portuguese Language teaching.

Keywords: formative politics; Portuguese; mato grosso.

\section{LA FORMACIÓN CONTINUA DE LOS PROFESORES DE PORTUGUÉS EN EL CONTEXTO DE MATO GROSSO/MT}

Resumen: El artículo propone discutir la política de formación docente en el contexto del Estado de Mato Grosso (MT). Para ello, observo los documentos guía y escucho a 02 profesores, graduados de ProfLetras, efectivos en la Red de Educación Básica. Mediante el análisis indico que hay que potenciar el diálogo y elegir formas de fortalecer el conocimiento de los profesionales de la enseñanza para contribuir en/para las prácticas lingüísticas cotidianas. Así, reflexionar sobre los desafíos y las contribuciones impuestas por las esferas gubernamentales, interpretar la formulación, la organización de la agenda formativa y verificar los resultados de estas acciones puede contribuir a cambios que corroboren para el (re)posicionamiento de las prácticas situadas de la enseñanza de la lengua portuguesa.

Palabras clave: política formativa; portugués; mato grosso. 


\section{Introdução}

Neste século, volumosos trabalhos científicos de secretarias federais, estaduais, municipais e Instituições de Ensino Superior (IES) sinalizam a premente necessidade de articular teoria e prática, reconhecer, valorizarizar o espaço/tempo da formação docente (FD) e observar os impactos causados em diversos contextos educativos.

O "novo panorama" visa, a priori, atender aos novos rumos de (des)aprendizagens exigidas pelo mundo contemporâneo.

Lamentavelmente, as condições dadas para a consecução destas políticas carecem de rotas que as tornem permanentes e de concretização de ações que, significativas, estabeleçam melhor interlocução entre alunos e professores e interfiram em sala de aula.

Nesse sentido, o governo brasileiro, em busca de atingir a meta 16, do Plano Nacional de Educação (PNE) para o período de 2014 a 2024, implantou o Programa em Formação Contínua em Rede Nacional stricto sensu (ProfLetras).

O ProfLetras é uma proposição de estreitamento do diálogo entre a Universidade e a Educação Básica, forma de projetar os/as professores/professoras a desenvolver maior reflexividade em suas práticas e melhorar os níveis de letramentos no Brasil.

Conhecer as contribuições governamentais neste trabalho é apresentar a escuta de duas colaboradoras de pesquisa, e engendrar uma proposta de (re)posicionamento das práticas situadas de ensino da Língua Portuguesa.

As colaboradoras de pesquisa são duas professoras egressas do ProfLetras Unidade de Sinop/MT, conforme o quadro demonstrativo 1 e, saliento, que a escolha dos nomes fictícios lembra a divisão topográfica da cidade de Sinop - MT, composta de nomes de árvores frutíferas, frondosas e flores muito facilmente encontradas na região.

Quadro 1- Grupo A - Colaboradoras - Professoras da Educação Básica, egressas do ProfLetras

\begin{tabular}{|llll|}
\hline Colaboradores & Formação & Tempo de atuação na & Ingresso no ProfLetras \\
\hline Colaboradora Castanheira & Graduação em Letras - & 11 anos & 2013 \\
& Português e Literaturas & \\
& Portuguesa e Brasileira & \\
\hline Colaboradora Nogueiras & Graduação em Letras - & 30 anos & 2013 \\
\hline
\end{tabular}

Fonte: Dados da pesquisa 
Considerando os questionamentos como método que suscita entendimentos, inicialmente, elaborei questões como: a) De que forma as políticas formativas do estado de Mato Grosso interferem/contribuem para o desenvolvimento profissional docente em Letras? b) Quais proposições/desafios o ProfLetras oferece aos alunos em formação?

Preliminarmente foram selecionados os documentos que regem a educação docente em Mato Grosso -MT, as Diretrizes da SEDUC/MT aos CEFAPROs e a portaria que rege o ProfLetras. Atenta aos processos metodológicos definidos por Bauer e Gaskell (2015), apliquei as entrevistas semiestruturadas às colaboradoras respeitando o espaço intervalar de um ano, para maior compreensão da representação e da construção da identidade docente, a reflexividade é aliada.

Embora haja uma complexidade em gerar os dados, tenho ciência, com Holliday (2016, p. 13), de que "Os métodos de coleta e análise de dados são as menores coisas que fazemos para realizar a nossa investigação [...]". Para o autor, muito mais importante é fundamentar-se nos dados, sistematicamente recolhidos, interagir continuamente, intercalando análise e envolver o participante no processo de reflexão.

Disponho no quadro demonstrativo 2 as perguntas elaboradas e aplicadas aos colaboradores:

Quadro 2- Questões dirigidas às egressas do ProfLetras - professoras efetivas da Educação Básica em Sinop (MT)

\begin{tabular}{|lll|}
\hline 1. Qual é a sua formação? & 2. Há quanto tempo você é professor de Educação Básica? \\
\hline $\begin{array}{l}\text { 3. Quando você começou sua Pós- } \\
\text { Graduação stricto sensu em Letras? }\end{array}$ & $\begin{array}{l}\text { 4. O que o ingresso no ProfLetras representa para a sua vida } \\
\text { pessoal e profissional? }\end{array}$ \\
\hline $\begin{array}{ll}\text { P. Qual(quais) proposição(proposições) o } \\
\text { Profletras trouxe à sua vida profissional? }\end{array}$ & $\begin{array}{l}\text { 6. Em que medida o Profletras interfere em sua prática de } \\
\text { sala de aula? }\end{array}$ \\
\hline $\begin{array}{l}\text { 7. Você se sente protagonista de suas } \\
\text { práticas docentes? Poderia exemplificar? }\end{array}$ & $\begin{array}{l}\text { 8. Que saberes, ao longo de sua formação stricto sensu, você } \\
\text { consegue visualizar sobre o ensino de Língua Portuguesa? } \\
\text { 9. Você percebe mudanças em seu fazer docente após a } \\
\text { conclusão do Profletras, ou elas ficaram restritas a quando você } \\
\text { era instigado às intervenções provocadas dentro das disciplinas e } \\
\text { no final de sua qualificação profissional? }\end{array}$ \\
\hline
\end{tabular}

Fonte: Dados da pesquisa

Nas últimas décadas, sustentei noutras discussões (ROQUE-FARIA, 2013, 2014, 2016) que ensejar políticas públicas voltadas ao contexto de formação induz condições producentes, projeção de atores/atrizes sociais à qualificação e à capacitação profissional, assim como incentiva as práticas emancipadoras e éticas de linguagem. Portanto, 
considero "as coisas ditas" e apreendo os caminhos que circunscrevem as condições para a docência, sem deixar de considerar as diferenças. Nesse paradigma, afirmo com a autora a necessidade real de:

[...] aceitar a raridade das coisas ditas (ou dos enunciados), trata-se certamente de uma espécie de atitude diante da vida, uma atitude ética e política, e também intelectual, pela qual assumimos que não há uma identidade entre nós mesmos e aquilo que investigamos, e que pensar é sempre navegar em meio às diferenças. (FISCHER, 2013, p.126).

Ouvir os sujeitos envolvidos na pesquisa e contrastar seus discursos pelos documentos orientadores traz lume às questões inicialmente apresentadas e consideradas centrais. Certamente, por mais que surjam ponderações sobre o processo da construção da identidade docente em LP não as considero únicas, mas insuficientes frente aos equívocos, à porosidade e ao contínuo movimento dado pela língua (PÊCHEUX, 2008, p. 51).

Inicio com os excertos retirados do Orientativo Pedagógico 2018 de formação do estado de Mato Grosso e com a Portaria Normativa no 17, de 28 de dezembro de 2009 ProfLetras, conjugada aos discursos dos pesquisados. Observo a provocação dada aos sujeitos envolvidos com o ensino de LP e, principalmente, o (re)posicionar desses professores, na tarefa de equalizar as desigualdades sociais, e, de igual modo, promover a educação linguística para a cidadania.

Certamente, nas questões práticas faltam maior investimento, ampliação de uma perspectiva formativa, plural e transformadora. Mesmo assim, as políticas públicas apresentadas nessa discussão, seja em nível nacional ou em nível estadual, constituem exemplos reais de alguns esforços. Nesse panorama, entendo-as como garantias asseguradas pela Lei de Diretrizes e Bases -LDB/96.

Especificamente na esfera estadual, em observância à LDB/96, por ação da Superintendência de Políticas de Educação Básica (SUEB) subordinada à Secretaria Adjunta de Políticas Educacionais (SAPE), o Estado de Mato Grosso regimenta a formação dos profissionais da EB e estabelece-se como fortalecedor das identidades profissionais por meio do Programa Pró-Escolas Formação na Escola (PEFE). 
O PEFE, (re)elaborado anualmente, (re)direciona e determina as estratégias de formação pedagógica de todas as unidades escolares do estado. Dentre tantas finalidades, também reafirma competências e atribuições dos profissionais da EB:

Esse programa representa a oportunidade para que os profissionais que se encontram em serviço nas escolas, a partir da formação de grupos de estudos, reflitam sobre as potencialidades e necessidades percebidas no contexto escolar e, a partir daí, formulem ações de intervenção voltadas à melhoria da qualidade do ensino. (MATO GROSSO, 2018, p. 107).

Assim, ao servidor público credita-se atenção ao processo de formação e o PEFE, estabelecido nas unidades escolares, canal potencializador e/ou maximizador da qualificação contínua no estado. Noutros caminhos, os diálogos dos formadores com os professores atuantes, o levantamento das situações formativas de cada realidade escolar e a criação dos grupos de estudos tornam-se "porta" para as interlocuções no interior do espaço escolar. Logo, os debates, por serem enriquecedores e centrados nas realidades, poderão motivar os professores, gerarão outros rumos e fortalecerão as identidades dos profissionais.

Apresentei em outra publicação (ROQUE-FARIA, 2016) que construir caminhos dialógicos requer ações contínuas e permanentes, ou seja, para além do mapeamento superficial, o que pode gerar decisões equivocadas, visto que o período exigido para a formação (80 horas) não deve achatar as necessidades emergidas no chão escolar.

Reconheço que as atuais condições por que passam a educação brasileira acabam por moldar/formatar/achatar a identidade docente. Por isso, ancoro-me na visão de Formação Permanente (FP), tão bem sinalizada em Imbernón (2009, 2010, 2011), que indica estabelecer condições formativas em diálogo com outros espaços de formação.

Assim, não basta estabelecer a escola como locus de formação, mas, entendê-la, a priori, em situações multidisciplinares, transversais, multidimensionais, transnacionais e globais. Também é preciso considerar que:

[...] a identidade profissional é uma construção individual e coletiva, razão pelas quais as constantes buscas, leituras e reflexões, a interação com os pares da área, com os professores da educação básica no contexto da formação que acontece no PSE, o envolvimento com os agentes formadores da própria SEDUC constituem-se aspectos 
reveladores de que as identidades das professoras formadoras da área de linguagens estão em contínuas mudanças, ou seja, em processo de construção. (SANTOS, RAMOS e SILVA, 2014, p. 407).

Entendo o PEFE como regulamentador de formação profissional em contexto situado de Mato Grosso, mas ressalto sua visão reducionista sobre as condições de provimento quanto à formação profissional. Significa que, pela obrigatoriedade das 80 horas de formação, os profissionais não dizem de si, mas "acatam" as ideias de outrem.

Certamente que a formação de professores é uma política estratégica e de interesse governamental. Mas deveria observar as multidisciplinaridades, as transversalidades, questões que implicam o global e o planetário (MORIN, 2011), a colaboratividade, a criticidade e a ética (FREIRE, 2000, 2005; ROJO, 2009, 2012), e primar pela qualidade e desenvolvimento permanente de seus profissionais em formação humana.

Santos (2016, p. 18), pesquisadora das Políticas públicas formativas no espaço pesquisado, indica que, embora haja pequenos avanços, "É necessário, pois, rompermos os paradigmas tradicionais que não se adequam às mudanças que movem a sociedade contemporânea e, simultaneamente, a educação e seus profissionais".

Pensando assim, reconheço que o Programa de Mestrado Profissional em Letras ProfLetras é o empreendimento de formação contínua, aprovado pela Coordenação de Aperfeiçoamento de Pessoal de Nível Superior (CAPES), em 2013, coordenada pela Universidade Federal do Rio Grande do Norte (UFRN) e conta com a significativa participação de 50 Universidades em todo o país.

Embora a afirmativa, as motivações contidas nos documentos orientadores de formação analisados (PEFE, ProfLetras) parecem ser guiadas por um fio condutor: o desnível linguístico dos alunos/alunas brasileiras e a inadequação de suas habilidades de letramentos impõem aos professores a ampliação formativa e a (re)adequação para atuar nas situações de ensino e para proporcionar uma mudança social.

Tais propostas, como enfatizei, desde a formulação até sua implantação visam investir nas potencialidades e nas capacidades dos sujeitos letradores. Por isso, reelenco os objetivos dispostos na Portaria Normativa no 17, de 28 de dezembro de 2009 que dispõe sobre o Mestrado Profissional e analiso frente aos discursos dos sujeitos envolvidos. 
Quadro 03- Objetivos do Mestrado Profissional

I - capacitar profissionais qualificados para o exercício da prática profissional avançada e transformadora de procedimentos, visando atender demandas sociais, organizacionais ou profissionais e do mercado de trabalho;

II - transferir conhecimento para a sociedade, atendendo demandas específicas e de arranjos produtivos com vistas ao desenvolvimento nacional, regional ou local;

III - promover a articulação integrada da formação profissional com entidades demandantes de naturezas diversas, visando melhorar a eficácia e a eficiência das organizações públicas e privadas por meio da solução de problemas e geração e aplicação de processos de inovação apropriados;

IV - contribuir para agregar competitividade e aumentar a produtividade em empresas, organizações públicas e privadas.

Fonte: BRASIL, 2009, p. 02, grifos meus.

É relevante salientar que as marcas verbais colocam em funcionamento a legitimação apontada em Thompson (2011), em verbos como "capacitar, promover e contribuir". O valor semântico, e isso carece maior fundamentação, corresponde à validação da Política fundadora de "uma nova era" e norteadora do princípio: (trans)formação ética e crítica. Todavia, o sentido é que, se não há prática educativa linguística ética e humanizadora e se os alunos não estão inseridos nos debates sobre os letramentos, os/as professores/as estão descontextualizados.

Para melhor constatação, continuo a visualizar as vozes dos discursos das colaboradoras, respectivamente, Castanheira e Nogueiras, são egressas do Curso de Letras da UNEMAT (Campus Sinop) e assumem o cargo de professoras efetivas em Língua Portuguesa na rede estadual do estado.

Em observância ao discurso, os sujeitos pesquisados (re)posicionam-se na/para a (re)construção da identidade. É relevante afirmar que, no contexto pesquisado, poucos programas de FC stricto sensu desenvolvem-se nesse espaço territorial. E mesmo que a UNEMAT atue em quase todos os municípios mato-grossenses $(13)^{2}$ a proposta nacional funciona em apenas 02 unidades, quais sejam, Cáceres (Sede da Universidade) e Sinop (região norte) situados em média 700 quilômetros um do outro e, de maneira autônoma, centram-se em suas peculiaridades formativas.

Ao reler os dados, notei, a priori, alguns aspectos peculiares: a) as pesquisadas confessam-se "alheias" ao teórico; b) o retorno à Universidade (des)estabiliza certas convicções práticas, gera inseguranças e produz o (re)posicionar-se profissionalmente.

\footnotetext{
${ }^{2}$ Cf. http://portal.unemat.br/numeros.
} 


\section{Vozes das alunas egressas do ProfLetras}

Geralmente, as interações linguístico-discursivas analisadas pela teoria social crítica não se mostram pelo óbvio, mas pela "captura" dos elementos significativos que emergem. E, compreendidos, pretendem a mudança social. Maciel $(2015$, p.105) orienta que as teorias críticas sinalizam "[...] desvelar como as desigualdades são criadas e sustentadas. Assim, investigam-se os processos pelos quais a desigualdade social é produzida e sustentada e o desafio é reduzir a desigualdade com o intuito de trazer a justiça social".

Portanto, para a continuidade da (re)interpretação das políticas públicas formativas, a partir dos documentos orientadores de formação e das vozes das colaboradoras envolvidas nesse processo, minha postura também se pauta nos pressupostos dados aos pesquisadores críticos: fomentar a formação de cidadãos éticos e pautar-me numa perspectiva que projete a (re)tomada de consciência (FREIRE, 2005, p. 252), da criticidade (MORIN, 2011), da emancipação (IMBERNÓN, 2011; ROJO, 2009) com vistas à mudança social (MOITA LOPES, 2006; PENNYCOOK, 2004).

Dessa forma, o discurso de Castanheira compõe as próximas discussões. Graduada em Letras, a colaboradora mudou-se em 2007 do Sul do país para o estado de Mato Grosso; seu ingresso na Pós-Graduação stricto sensu se deu em 2013 e a conclusão em 2015. Professora efetiva da EB pública estadual, também atuou por um período curto na UNEMAT (Campus Sinop). O quadro 04 apresenta suas respostas:

Quadro 04- (E 01, Castanheira, 12/05/17)

\section{Sentidos da proposição governamental}

(01) Uma conquista pessoal, sempre foi um desejo, né, fazer essa especialização, esse curso de Mestrado. E profissionalmente acarreta outras possibilidades, abre novas portas, sem contar novas questões de conhecimento, novas práticas em sala de aula.

(02) Durante o curso todas as atividades, elas foram voltadas para as práticas em sala de aula. Acho que é um grande diferencial que esse programa tem. Sei que foram voltados para a sala de aula, uma reflexão muito das práticas que a gente vinha fazendo, como foram feitas, o quê que podia melhorar, aprimorar. $E$ as questões teóricas subsidiaram as práticas. Então, assim todas as disciplinas voltavam uma atividade prática, praticamente, a partir da teoria estudada. E aí fazíamos a prática, trazíamos o retorno, havia um debate, uma reflexão.

Interferências do ProfLetras e as práticas diárias

(03) Mas, como momento de (...) reflexão de (...) como fazer. Não é que antes não se tinha as mesmas práticas, tinha coisas que já eram pra ser feitas, já eram pensadas, já eram realizadas. Mas, praticamente todas as ações são feitas na escola, ou especificamente na sala de aula, sempre vem a carga, né, do que foi estudado e do que foi proposto durante o curso. Então, né, assim parece que na (/) foram conhecimentos adquiridos a mais, que geraram uma responsabilidade maior. Tipo assim, uma responsabilidade... você tem um conhecimento, você sabe então...você não vai lá apenas para cumprir um horário. Você sabe qual 
é a sua responsabilidade, não que isso antes não acontecia, mas agora o olhar é outro.

Criticidade e Protagonismo

(04) Sim, eu me sinto protagonista. Mas, assim, eu acho que sempre me senti protagonista, porque eu sempre me envolvi muito nas atividades com os alunos. Então, era dado uma atividade, "deixa eu fazer", sempre teve um envolvimento, uma participação e eu acho que o mais importante de se perceber como protagonista é perceber que o aluno também é. Esse foi um dos legados do curso, né. De saber que o aluno não é um ser passivo ali na sala de aula, que ele tem vontades, que ele tem responsabilidades e que ele é capaz de fazer.

Sala de aula e o ensino de LP

(05) Espaço interação, de socialização de conhecimento, de trocas, né. Então, assim, conforme a gente vai com um tipo de conhecimento e o aluno vem com outro, traz indagações que faz a gente buscar também né, novas respostas, então, eu acho que é essa interação que eu falo.

Saberes construídos e interações em sala de aula

(06) Espaço interação, de socialização de conhecimento, de trocas ${ }_{L}$ né. Então, assim, conforme a gente vai com um tipo de conhecimento e o aluno vem com outro, traz indagações que faz a gente buscar também né, novas respostas, então, eu acho que é essa interação que eu falo.

(07) Então tá, você tá falando especificamente em relação a Língua, de ensino da Língua Materna de perceber que esse espaço sala que é o espaço de interação, ele deve ser (/) a Língua deve ser tratada social e interativo. E não apenas com um ensino de regras, mas como essas regras se aplicam no discurso, no texto, eu acho que esses são os maiores saberes que mudou e a gente traz para a sala de aula, né, de Língua Portuguesa. De perceber que a Língua ela é vida, dinâmica e que na própria (...) no próprio (+) no próprio processo de ensino/aprendizagem nós utilizamos a língua, né, a língua, a linguagem. Vê quais são as linguagens que os alunos estão utilizando, como que eles veem. Tanto que meu trabalho partiu (/) ele focou muito no texto multimodal, porque eu percebi o quê? Que o aluno gosta muito da multimodalidade, do visual. Mas, não conseguia fazer uma leitura profunda do visual, era uma leitura mais superficial.

(08). Utilizo-me mais da Linguística Aplicada. (...) eu percebo que (...) que se encaixa mais nas minhas práticas, né. Que vou propondo um produto social, caracterização social, a questão discursiva, a discussão que se abre dentro da LA, que não é um campo fechado, né. Abre, então, mais possibilidades de buscar em outras (...) vertentes quando eu preciso (...)

(09) (...) dentro da sala estudando a gente percebe (...) vê qual vai ficar melhor. Então, assim, uma das coisas do programa foi a quantidade de disciplinas e o tempo (...) o tempo para o projeto em si. Que era de pesquisa-ação e que toma muito tempo. Então, assim, para o projeto ficou pouco tempo com atividades, assim, bem corridas para dar tempo de terminar.

(10). É que o Programa se propõe para uma formação do professor em sala de aula. E em sala de aula eu vou trabalhar todas as disciplinas que tivemos, entendeu? Então, contempla. Nesse sentido contempla. Porque eu vou trabalhar Literatura Juvenil, eu vou trabalhar Literatura Brasileira, eu vou trabalhar todas essas disciplinas que no meu projeto não tinha. Porque ele não abarcava Literatura, é um exemplo só. Então, é nesse sentido que eu falo.

Fonte: Dados da pesquisa

Com base nas ponderações da colaboradora, regressar à Universidade é a representação e a confirmação da proposição formulada: (re)posicionar sujeito frente aos conhecimentos e fomentar a reflexão identitária, o que subjaz o pessoal e o profissional. O compromisso com o ensino de LP e a ansiedade pela oportunidade da formação stricto sensu induz a colaboradora a transportar-se da função social de professora para a posição de coautora, comprometida pelo "conhecimento, novas práticas em sala de aula".

Na voz da colaboradora o ProfLetras é revitalizador, dinamizador das identidades e mobiliza o sujeito a estabelecer a sala de aula como laboratório, promovendo um fazer 
em consonância com as novas teorias e metodologias apropriadas ao contexto de situação

A posição identitária assumida expressa que o fortalecimento da identidade se dá a partir do enfrentamento, do reelaborar, do repensar para atuar com autonomia, pois "as questões teóricas subsidiaram as práticas". Ao sugerir a inovação no ensino e na aprendizagem, Imbernón (2012, p.114-115) alude à necessidade de facilitação dos espaços de formação (Universidade) e acrescento, o espaço da EB, como lugar de reflexividade. Para o autor, isso inclui "eliminar inércias e ideologias obsoletas" e maior envolvimento com o coletivo.

Castanheira reafirma o ProfLetras como política capaz de provocar mudanças e interferir diretamente nas situações de ensino de LP reiterado no excerto 03. Alhures afirmei (ROQUE-FARIA, PRECIOSO, 2016) a importância da FC nacional. Entendi que o espaço de interação entre aluno e professor e a integração dos conhecimentos teóricos e práticos desencadeiam, estrategicamente, uma mudança discursiva e a fazem assumir a posição de sujeito-professor para sujeito-pesquisador.

Concordamos que a formação nacional deve prover condições para a construção de conhecimento reatualizado, renovável, confrontador, e promover espaços para debates e ações que ampliem a compreensão das realidades sobre a educação brasileira, a educação local, alargando a visão dos participantes, seja em pré-serviço ou em serviço, e transcender os discursos "já ditos" e propiciar a ressignificação para além dos bancos escolares. (ROQUE-FARIA, PRECIOSO, 2016, p.38).

Por diversas vezes, a colaboradora Castanheira, assume-se protagonista de seu fazer, reiterado pela preocupação em rever suas ações e por um fazer teorizado no excerto 08. Para desenvolver a aprendizagem, a colaboradora entende que, teoricamente, necessita reescrever caminhos que proporcionem a (re)adequação de seu fazer.

Tal fato não lhes confere o status de agentes críticos, embora assumidamente comprometidos com a mudança social. Eis por que afirmei que, no imaginário coletivo, há uma ideologia sustentada de que a formação stricto sensu - ProfLetras - "chancela" o fazer cotidiano dos professores. Prefiro aliar-me à Freire (2004, p. 146) para quem "[...] a prática docente implica certa sabedoria que vai se constituindo na gente, à medida que a gente vai constituindo a experiência de ensinar e de aprender". 
Faria, R.J.H.

Nogueiras, a segunda colaboradora também egressa do ProfLetras, se afirma dedicada à educação linguística há 30 anos, também atua como docente em uma Instituição Superior particular no município de Sinop. Seu ingresso no Mestrado Profissional também ocorreu em 2013. Disponho o discurso no quadro abaixo:

Quadro 05- (E 02, Nogueiras, 12/05/17) Sentidos da proposição governamental (11) Para minha vida pessoal é uma realização. Essa possibilidade de recomeçar os estudos, de ampliar as qualidades de conhecimentos. Seguir as noções mais recentes, uma vez que minha Graduação é de bastante tempo já, sou graduada lá em 1993. A vida profissional, obviamente, representa a possibilidade de você rever sua prática, melhorar em alguns aspectos, observar de maneira mais crítica aquilo que você vem fazendo com vistas às melhorias.

(12) A proposição maior é no sentido de fazer observar a necessidade que o grupo de professores de língua, de fato, reveja sua prática. De que há uma necessidade de contemplar o texto com maior propriedade no ensino da Língua Portuguesa.

Provocações/Interferências a partir do ProfLetras

(13) De que maneira ele tem interferido na prática? (+) Eu penso, primeiramente, renovando o ânimo. Porque, com as discussões possibilitadas pelo Profletras, algumas práticas que já são comuns mostram-se acertadas, isso das quais, eventualmente, até se teoriza com mais propriedade a partir do ProfLetras. Em outro ponto ele possibilita que você ajuste ou se aperfeiçoe naquilo que você vem fazendo e busque, realmente, meios de tornar mais eficiente esse ensino da Língua junto a essa meninada.

Saberes construídos e aplicados no espaço de LP

(14) Eu me sinto! Protagonista que eu digo (...) no sentido assim (...) de ser dona da minha aula. De observar situações que ocorre na própria sala de aula, que eu posso tomar como objeto de situação, objeto de reflexão. (...) É no sentido de observar tudo que acontece na sala de aula, Eu penso que é nesse sentido que eu busco trabalhar com os meninos e vou inventando modos, diferentes estratégias de fazer isso acontecer, e não ficando presa ao livro didático ou apostila. Enfim, mas é observando o que funciona, é procurando incrementar naquilo que está proposto, na intenção que os alunos também estejam ansiosos para terem essa aula de Língua Portuguesa. Assim... de uma maneira mais prática, de uma maneira bem mais produtiva.

Contribuições no/para o ensino de LP

(15) Bem (...) eu penso em junções propiciado pelo ProfLetras, de ignorar todo aquele contexto (...) digamos (...) aí fugiu a palavra (+) Mas aquelas situações que são meio é (...) coadjuvantes da aula de Literatura e de colocar como protagonista da aula de Literatura de fato o próprio texto, a fruição do texto. Eu penso que isso é uma situação que o ProfLetras me trouxe de maneira bem clara e mostra que minha ânsia de fazer isso, de fato tem sentido e precisa ser buscado para que isso se concretize de maneira mais efetiva. E, em relação à produção de texto, eu penso que, com algumas discussões que a gente teve, é fazer com que o aluno também olhe para seu texto, né? A questão da Metacognição, do aluno observar e perceber no texto dele a partir do apontamento do professor o que ele deve melhorar, quais os caminhos para melhorar isso._Ter o texto como (...) suporte que possa ser melhorado para que ele seja mais claro, mais dentro daquilo que foi proposto. E não unicamente um texto que é produzido, que é corrigido, que é lançado uma nota.

Fonte: Dados da pesquisa.

Os sentidos dos discursos apresentados em Castanheira assemelham-se ao de Nogueiras. Para a colaboradora, o processo de construção da identidade de um profissional engloba tanto a vida pessoal quanto profissional. A aquisição do conhecimento também representa a possibilidade de reavaliar, com criticidade e 
autonomia, as costumeiras práticas de ensino. A colaboradora considera que os sentidos de formação inferem na valorização de si mesma e na revisão permanente de suas práticas. Na discussão de caminhos para a educação inclusiva, Freire (2009, p. 114) apontou a grande carência no meio profissional de pensar e agir com criticidade. $\mathrm{O}$ autor advoga que, "Se a compreensão é crítica ou preponderantemente crítica, a ação também o será".

Nesse sentido, observo a colaboradora em reflexão sobre si mesma fundamentada na afirmação de que, para atuar no cenário de ensino de LP, os profissionais precisam compreender e usufruir de novas habilidades cognitivas, sociais e profissionais. Ela ressalta o ProfLetras como uma direção facilitadora das condições pessoais e profissionais. A colaboradora pondera a proposta formativa como significativa, oportunizadora das novas tendências de ensino/aprendizagem e fortalecedora do viés teórico-metodológico. Para além, "necessidade que o grupo de professores de língua, de fato, reveja sua prática".

Noutra via, isso significa o fortalecimento do profissional em Letras e, assim, despertar o cidadão brasileiro para agir com criticidade e valorizar a interação na/pela língua, pois

É oportuno lembrar que a escola deve usufruir do momento de inovações tecnológicas e modernizar suas práticas e propostas de ensino/aprendizagem, tanto na forma quanto no conteúdo, atendendo as reais necessidades impostas pelo mundo dinâmico e globalizado a que estamos submetidos. Cabe ainda dizer que a educação atual exige reflexão das práticas pedagógicas[...] (FREITAS; ROQUE-FARIA, 2014, p. 271).

Acredito que, com as inovações tecnológicas, no mundo dinâmico e globalizado, a maior e complexa contribuição do ProfLetras reside em instalar novas dúvidas, desafiar, constantemente, os profissionais a se tornarem competentes, valorizar a si mesmos e aos outros. Realimento aqui a ideia descrita noutro espaço. A FC provê condições:

[...] para a construção de conhecimento reatualizado, renovável, confrontador, e promover espaços para debates e ações que ampliem a compreensão das realidades sobre a educação brasileira, a educação local, alargando a visão dos participantes, seja em pré-serviço ou em serviço, e transcender os discursos "já ditos" e propiciar a ressignificação para além dos bancos escolares. (ROQUE-FARIA, PRECIOSO, 2016, p.38). 
Neste sentido, os espaços de debate, de revisitação às práticas, de confrontação ainda se fazem urgentes, por isso é necessário que, de fato, (re)organizem os contextos locais e elucidem-se situações adequadas e eficazes de ensino-aprendizagem. Tomo por base Dolz e Hardmeyer (2016, p. 83) que analisam os desafios para o ensino de LP e a formação de professores no Brasil. Do ponto de vista sociocultural, variacionista e interacionista, os autores explicam "que ensinar uma língua é estar atento à apropriação de capital social e cultural pelo aprendiz".

Na posição protagonista de suas ações, a colaboradora Nogueiras, em exercício de autocrítica, retoma seu papel social e indica a observação da prática para o melhor funcionamento do ensino. Corrobora as palavras de Tardif (2012, p. 20), "ensinar supõe aprender a ensinar, ou seja, aprender a dominar progressivamente os saberes necessários à realização do trabalho docente".

Ressoando Libâneo (2011, p.53), na cadeia produtiva da profissionalização docente, "A escola de hoje precisa não apenas conviver com outras modalidades de educação não formal, informal e profissional, mas também articular-se e integrar-se a elas, a fim de formar cidadãos mais preparados e qualificados para o novo tempo".

As egressas do ProfLetras percebem que as ações do ProfLetras interpelam o sujeito na (re)construção da identidade, seja na esfera pessoal ou na profissional. E, impactado à autocrítica, há possibilidades de o professor tornar-se pesquisador de suas práticas, mais zeloso no fazer teórico-metodológico e aberto às novas teorias da linguagem. Adaptar-se às realidades de ensino da LP, concordando com os pressupostos da atualidade, o que também é desafiante.

\section{Conclusão}

Ciente do papel social e atenta aos nichos formativos, centrei nas inquietações que considerei essenciais, as quais me colocam em constante reflexão. Especificamente tratei das questões que cercam o cenário formativo. Esforcei-me em conhecer, por um conjunto discursivo - os documentos orientadores de políticas públicas de formação (PEFE e ProfLetras) e os discursos das colaboradoras, as complexidades, os múltiplos sentidos que envolvem o "saber" e o "fazer" docente refletido no papel dos atores e das atrizes atuantes no locus pesquisado. 
Pelos documentos orientadores observei que os discursos anunciados distanciam-se dos discursos professados, entretanto ratificam e positivam as políticas de formação como essencial para a construção da identidade docente. Na tentativa de dar visibilidade a alguns sentidos que emergiram, respaldei-me em teorias sociais e entendi com Gimenez (2017, p. 49) que ao profissional e/ou ao futuro profissional em Letras, seja em formação inicial ou contínua, muitas situações usualmente vivenciadas na educação linguística precisam ser problematizadas e apreendidas em suas complexidades.

Pela análise dos dados, evidenciei que a formação acadêmica pressupõe políticas públicas produtivas, ininterruptas e contribuidoras para mudança social. Tais mudanças só serão possíveis por meio do discurso das políticas formativas em Letras engendradas no Brasil, que corroboram para o discurso de validação do perfil profissional, o qual se apresenta fortemente marcado pela "qualificação" e "instrumentalização".

Dessa forma, apontei que, os discursos analisados dos professores atuantes em Língua Portuguesa da EB estão permeados de inquietações, o que desestabiliza a ordem das coisas e faz que o sujeito construa lugares colaborativos e éticos da profissão. Sendo a premissa "preparar, instrumentalizar, qualificar", de maneira reiterável, reverbera e legitima as práticas dos/das professores/as, tanto na posição de sujeito-formador quanto na posição de sujeitos formandos e formados.

Compreendi que os sujeitos colaboradores de pesquisa se apresentam afetados pelas políticas públicas e, unânimes, reconhecem a necessidade de desconstruir as fronteiras entre o teórico e o prático, entre a Universidade e a Escola, entre o formador e professores em situação de formação. O contexto de educação linguística carece de construções dialógicas de formação, a fim de possibilitar condições que atendam as práticas situadas de ensino de LP e ampliar as capacidades e habilidades do professor como pesquisador de suas práticas.

O tema é inesgotável em sua extensão e profundidade, embora muitos debates e discussões na atualidade contribuam para abertura de novas frentes. Reconheci que esse assunto tem sido desenvolvido em perspectivas teórico-metodológicas variadas, mas a educação linguística no Brasil ainda espera respostas no que se refere ao índice de letramento dos/das alunos/as brasileiros/as. 
O ProfLetras, embora seja uma ação governamental recente, incorpora à vida pessoal e profissional do sujeito em Letras a capacidade de reposicionar-se frente aos desafios de ensino da linguagem. Todavia, o discurso institucionalizador, regulador e orientador da formação em Mato Grosso, vale ressaltar, em fragilidades, ainda indica que o movimento contínuo se torna condição para (re)construir as identidades profissionais e provimento de espaços para o ensino de LP de forma humanizadora, quiçá, tradução de criticidade.

\section{Referências}

BAUER, M. W.; GASKELL, G. (org.). Pesquisa qualitativa com texto, imagem e som: um manual prático. Tradução de Pedrinho Guareschi. 13. ed. Petrópolis, RJ: Vozes, 2015.

BRASIL. Decreto no 6.755 de 30 de janeiro de 2009. Institui a Política Nacional de Formação de Profissionais do Magistério da Educação. In: Diário Oficial da República Federativa do Brasil: seção 1, Brasília, DF, 29/01/2009. Disponível em: http://www.capes.gov.br/images/stories/download/legislacao/Decreto6755_2009.pdf

BRASIL. Ministério da Educação e Cultura. Leis de Diretrizes e Bases. Lei no 9.394, de 20 de dezembro de 1996. Estabelece as diretrizes e bases da educação nacional. Diário Oficial da União, Brasília, DF, p. 27.833, 23 de dez. 1996. Disponível em: http:// www.planalto.gov.br/ccivil_03/Leis/L9394.htm. Acesso em: 06 de outubro de 2016.

FISCHER, R. M. B. Foucault. In: OLIVEIRA, L. A. (org.). Estudos do Discurso: perspectivas teóricas. 1. ed. São Paulo: Parábola, 2013.

FREIRE, P. Educação como prática da liberdade. São Paulo: Paz e Terra, 2009.

FREIRE, P. Pedagogia do Oprimido. Rio de Janeiro: Paz e Terra, 2005.

FREIRE, P. Pedagogia da tolerância. São Paulo: UNESP, 2004.

FREIRE, P. Pedagogia da indignação: cartas pedagógicas e outros escritos. São Paulo: UNESP, 2000.

FREITAS, E. D. S.; ROQUE-FARIA, H. J. Tecnologias de Informação e o ensino de Língua Portuguesa na EJA. In: SANTOS, L. I. S., JUSTINA, O. D., JUSTINA, T. D. (org.). Linguagens em foco: crenças, discurso e ensino. Campinas, SP: Pontes, 2014. p. 243-270.

GIMENEZ, T. Aproximando a Linguística Aplicada crítica à sala de aula. In: JESUS, D. M.; ZOLIN-VEZ, F.; CARBONIERE, D. (org.). Perspectivas críticas no ensino de línguas: novos sentidos para a escola. Campinas, SP: Pontes Editores, 2017.

HOLLIDAY, A. Doing \& writing. Qualitative research. 3. ed. CPI Group (UK)Ltd, 2016. 
IMBERNÓN, F. Inovar o ensino e a aprendizagem na Universidade. São Paulo: Cortez, 2012.

IMBERNÓN, F. Formação docente e profissional: formar-se para a mudança e incerteza. Tradução Silvana Cobucci Leite. 9. ed. São Paulo: Cortez, 2011.

IMBERNÓN, F. Formação continuada de professores. Tradução Juliana dos Santos Padilha. Porto Alegre: Artmed, 2010.

IMBERNÓN, F. Formação permanente do professorado: novas tendências. Tradução Sandra Trabucco Valenzuela. São Paulo: Cortez, 2009.

LIBÂNEO, J. C.; OLIVEIRA, J. F.; TOSCHI, M. S. Educação escolar: políticas, estruturas e organização. 10. ed. São Paulo: Cortez, 2011.

MACIEL, R. F. Letramento Crítico das políticas linguísticas e a formação de professores de línguas. In: TAKAKI, N. H.; MACIEL, R. F. (org.). Letramentos em terra de Paulo Freire. Campinas, SP: Pontes, 2015. p. 101- 114.

MATO GROSSO. Orientativo Pedagógico para 2018. Cuiabá, MT: SEDUC, 2018.

MOITA LOPES, L. P. Linguística aplicada e vida contemporânea: problematização dos construtos que têm orientado a pesquisa. In: MOITA LOPES, L. P. (Org.). Por uma Linguística Aplicada Indisciplinar. São Paulo: Parábola, 2006. p. 85-107.

MORIN, Edgar. Os sete saberes necessários à educação do futuro. Tradução Catarina Eleonora F da Silva e Jeanne Sawaya; Revisão Técnica Edgard de Assis Carvalho. 2. ed. rev. São Paulo: Cortez; Brasília, DF: UNESCO, 2011.

PÊCHEUX, M. Discurso: estrutura ou acontecimento. 5. edição. Tradução Eni P. Orlandi. Campinas: Pontes, 2008.

PENNYCOOK, A. Critical applied Linguistics. In: DAVIES, A; ,ELDER, C. The handbook of applied linguistics. Oxford: Blackwell Publishing, 2004.

ROJO, R.; MOURA, E. (org.). Multiletramentos na escola. São Paulo: Parábola, 2012.

ROJO, R. Pedagogia dos Multiletramentos. In: Letramentos Múltiplos, escola e inclusão social. São Paulo: Parábola, 2009.

ROQUE-FARIA, H. J. (Des)encontros na formação docente na/para a EJA: reflexões sobre o curso de Letras, o PIBID e o Projeto Sala de Educador. Dissertação (Mestrado em Linguística) - Programa de Pós-graduação em Linguística, UNEMAT, Cáceres, 2014. Versão impressa e eletrônica. Disponível em:

http://portal.unemat.br/media/oldfiles/linguistica/docs/dissertacoes2014/helenice_jovia no_roque_de_faria.pdf. Último acesso em: 10 jan. 2019. 
ROQUE-FARIA, H. J Letramentos e Gêneros. In: SANTOS, L. I. S.; SILVA, K. A. (org.). Linguagem, Ciência e Ensino: desafios regionais e globais. Campinas, SP: Pontes, 2013. p. 251-264.

ROQUE-FARIA, H. J.; PRECIOSO, A. L. As políticas de formação docente em contexto de Mato Grosso: PIBID e PROFLETRAS. In: SÁ, R. L.; SOUZA, E. M. F.; MORAES, E. M. A. (Org.). Políticas de ensino-aprendizagem: enfoques nos objetos e na formação docente. Campinas: SP: Pontes, 2016.

SANTOS, L. I. S. Unidades Mato-grossenses do PROFLETRAS: abrangência, resultados e perspectivas. Letras \& Letras, Uberlândia, v. 32, n. 2, jul./dez. 2016. Disponível em: http://www.seer.ufu.br/index.php/letraseletras/article/view/35127/19941. Último acesso em: 10 jan. 2019.

TARDIF, M. Saberes docentes e formação profissional. 12 ed. Petrópolis, RJ: Vozes, 2012.

TELLES, J. A. "É pesquisa, é? Ah, não quero, não, bem!" Sobre pesquisa acadêmica e sua relação com a prática do professor de línguas. Linguagem \& Ensino, v. 5, n. 2, p. 91-116, 2002.

THOMPSON, J. Ideologia e cultura moderna: teoria social crítica na era dos meios de comunicação de massa. Petrópolis, Rio de Janeiro: Vozes, 2011. 